\title{
Application Features of Thyristor Regulators to Control the Light Flux in Industrial Fishing
}

\author{
E.P.Matafonova ${ }^{1}$, S.B.Burkhanov ${ }^{1 *}$ \\ ${ }^{1}$ Far Eastern State Technical Fisheries University, 690087, Vladivostok, Russia
}

\begin{abstract}
To control the intensity of the light flux when fishing saury it is necessary to widely change the voltage of the lighting fishing equipment. It is reasonable to carry out this by controlling additionally installed thyristor regulators supplying individual symmetric three-phase groups of light sources that will ensure balanced loading of the synchronous generator stator windings. In this research the features of using a thyristor voltage regulator in a four-wire system of ship power supply are studied based on mathematical analysis, conclusions are made using computer modeling and the use of current limiting reactors is justified.
\end{abstract}

\section{Introduction}

A lighting equipment on modern ships is effectively used while shipboard cone purse net fishing and also while fishing with the help of fish pump equipment.

A lighting equipment while shipboard purse seining is used for fish detection, fish attraction to the ship, moving the fish from one shipboard to another one, where the purse seine is fixed, fish concentration in purse seine area. So, to detect saury and to shift it to the area of other above-water equipment, they install on the ship about three searchlights with a capacity of 1-3 kW each. To detect fish low-angle dispersion searchlights with major range coverage are used, and to shift fish closer to the shipboard they use high angle dispersion searchlights. The range coverage of searchlights is $1 \mathrm{~km}$.

Saury is attracted by the overwater lighting lamp to the non-operational board side and is shifted then to the operational board side, where the purse seine is fixed. The lamps are fixed on boat booms on both board sides. The boat boom construction ensures fixing the lamps on a proper distance from the shipboard, changing the angle of lam declination, etc.

Lamp positioning, its amount, the number of bulbs in each lamp depend on class of ship and power of ship's electric power plant. For example, on Japanese saury fishing boats the saury fishing equipment includes: 76 lamp sets to attract saury $(0,5 \mathrm{~kW}$ x 36pcs.), 18 sets $(0,5 \mathrm{~kW} \times 24 \mathrm{pcs}$.), and also searchlights to search saury - 2 pcs $7-7,5 \mathrm{~kW}$ each [1]. Russian research vessel "Vladimir Safonov" (project STR 420) has a standard saury lighting fishing equipment with a capacity of $145 \mathrm{~kW}$ : $115 \mathrm{KGP}$ haloid incandescent lamps, halogen spotlights (19 line lights, 8 by-pass lights), 40 diode red and white lights, string of 12 ligths $60 \mathrm{~kW}$ each, etc. [5]. In general, the combination of lights of different capacity is needed on

* Corresponding author: burkhanov@list.ru 
search and fishing boats (such as medium refrigerator trailers and seiner-trawler) to create photic zone of different size and forms of the water.

The overwater lighting system is supposed to turn on and off all lamps, including lamp groups, single lamps and part of lamp bulbs (fig.1) [2]. Panel boards and signal panels are developed for saury purse seine fishing.

Saury fishing needs an overvoltage of lighting equipment at different period of fishing, for example, when the moon is active the voltage is maximum - till $260 \mathrm{~W}$, when it's foggy the volt-age is minimum (the lamps are underheating) - till $100 \mathrm{~W}$. There is a high tendency of increasing the fixed lamp voltage that can reach $800-1000 \mathrm{~kW}$ in future.

General requirements to the lighting equipment, which has different functions during purse seine fishing, are the following: the consideration of spectral structure, light scattering angle, fishing spots, and also its operating conditions, which depends on type of fish, the period of fishing, the intensity of the moon light, the atmosphere transparency, the transparency of water etc.

At the moment, the volume of migrating saury in Russian sea waters is estimated at approximately 1 million tons. This allows local fishers to fish not less than 120 thousand tons per year. However besides some biological factors that make the saury fishing one of the most difficult one (the unstable shoal of fish, regular school relocation, the need in search), the competitiveness is very high- the fishers from Japan, South Korea, Taiwan and China are getting too fast in saury fishing. [3].

The development of domestic shipbuilding is aimed to combine the industrial saury fishing instruments with other types of fishing tools (with lighting equipment) to fish horse mackerel, mackerel, sprat, squid and other fish sensitive to the light of surface and underwater equipment. [4].

In the long term, the goal is to develop the shoaling search automation system, to engineer new fishery schemes, and also to advance the mechanization tools and the ways of automatic management of lighting fishing electrical system.

The aim of this paper was to determine recommendations of calculation the compensating devices parameters and application of thyristor convertors of lighting fishing equipment of four-wire system of electric supply. To achieve this goal the authors have analyzed the literature data, performed theoretical calculations and computer simulation of the objects of investigation.

When applying existing modeling software of electrical and electronic circuits with lineal and nonlinear elements (coils, capacitors, thyristors, etc), we have to take into account the peculiarities of circuits, that is why the calculation of dynamic electronic circuits needs a preliminary mathematical analysis.

\section{Results and discussion}

When saury fishing in Far Eastern seas on domestic boats like STR type ships, the most popular are KGP-220/1500 lamps (fishing tungsten-halogen quartz lamps) of 22 lumen/W, which have hermetically sealed bushing of random position lighting angle (till $45^{\circ}$ ), which allows to set the lamps along the board to get a continuous light line [5]. These lamps are resistant to voltage drop - till $240 \mathrm{~W}$, and with $220 \mathrm{~W}$, they have a light temperature of $3000^{\circ} \mathrm{C}$.

STR type vessels are equipped with $80 \mathrm{~kW}$ thyristor regulators, which are used for multistage circuit application - on one board (lighting) one voltage is being regulated, on another board (working)- another one.

Fig. 1 shows the installation scheme of saury fishing lighting equipment on STR vessels, where 1- optional lighting strings; 2 - lamp switch; 3 - light flux control panel; 4 - a searchlight PP-90; $5-9 \mathrm{~kW}$ bypass flash (6 white KGP lamps); $6-2$ lamps with 3 KGP- 
1500 each; 7 - in-creased power lamp (18kW); 9 - concentrating lamp ( 3 white 4,5 kW lamps $+2 \operatorname{red} 4,5 \mathrm{~kW})$.

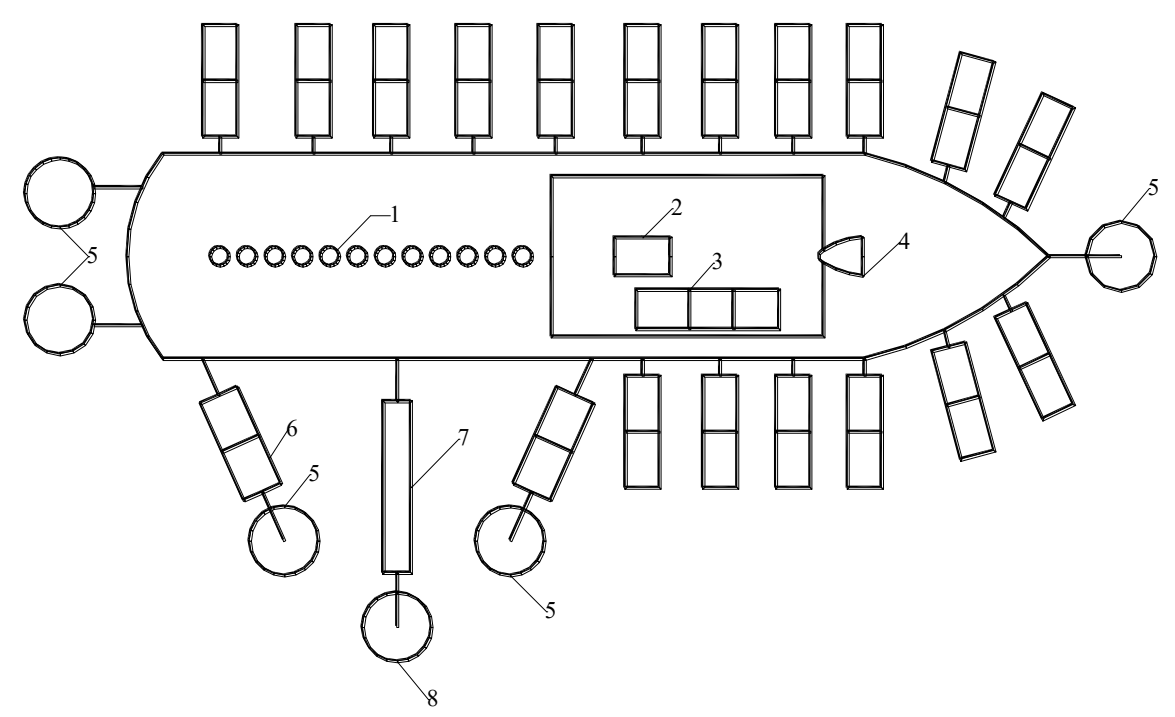

Fig. 1. Installation scheme of saury fishing lighting equipment on STR vessels.

The lamps are fixed on different levels. Different types of lamps are implemented. For ex-ample on the highest level the increased power lamps like KGP $-220 \mathrm{~W} 18 \mathrm{~kW}$ are fixed, which at-tract shoal of saury on larger surface - a general diffused lighting. With their help saury goes to the main lighting area. As soon as saury is getting close to the light of board lamps $(4,5 \mathrm{~kW})$ which are fixed along the perimeter of the ship, they start to shift saury through the ship foredeck from the right board to the left one (lighting board) by consequently switching off the lamps. The lamps are getting switched off one by one from the sides to the center, the switch-on (switch-off) sequence is applied when saury is moved to the trap area, which is being done smoothly in two phases.

As soon as the main shoal is in the area of catching equipment, they switch on the red light of specific spectrum ( 3 red 4,5 kW lamps - red quartz), with the help of which the fish is gathering in the trap area even more, and then they use the catching tool.

So, the main tendency of saury fishing is the following: the light source has to be of 250$300 \mathrm{~kW}$; the light flux has to be controlled not only by different number of lamps, but by the change of their voltage at the range $(0,3-1,1)$ from $220 \mathrm{~W}$, which allows to change the spectral light quality and is the important factor of fish concentration and managing its behavior.

The main characteristics that a vessel has to have to control voltage are sustainability and minimization of mass-dimensional indicators of device; the need to uniformly distribute all load in phases (load imbalance must not exceed the power of one lamp, that means $12 \mathrm{~kW}$ ).

Under modern conditions the required voltage change (when the lamps are on and off in a specific sequence, lowering the other lamps voltage by several times to the nominal) is carried out by managing by thyristor voltage regulators [7], supplying single symmetric triphase light source groups.

This condition provides a balanced load of synchronous generator stator windings. As light source nominal voltage amounting to the electric line voltage loss in is less than the nominal generator voltage, then with the insertion light source to the triangle the generator will appear just as much to be power underused. For the full load of generator the lamps with the light source have to be included into the star, as shown on Fig. 2, where: $\mathrm{e}_{\mathrm{A}}, \mathrm{e}_{\mathrm{B}}, \mathrm{e}_{\mathrm{C}}-$ 
generator voltage; $Z_{A}, Z_{B}, Z_{C}$ - generator and line resistance; $T K$ - thyristor keys; $R_{a}, R_{b}, R_{c}$ - load resistance (lamps); $Z_{f}$ - resistance of tuned filters of compensation filter device.

With generator zero lead insulated load neutral $(\mathrm{ZN}=\infty)$ its imperfect symmetry that appears with different number of lamps switched off in different load phases causes unsymmetry of load star voltage.

In the meantime, the effective value of voltage in phase of the most load resistance is outside the limits. To avoid this we have to apply a four-wire system of electrical supply where the load neutral is connected to the generator zero lead.

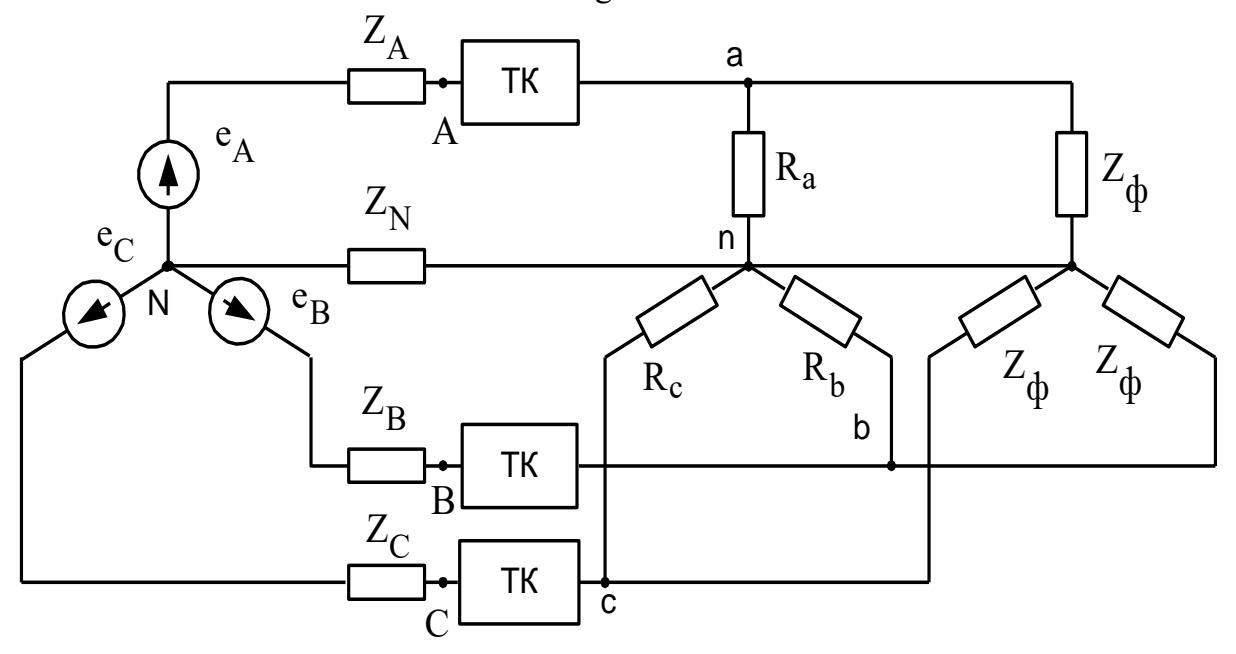

Fig. 2. Fish search light source electrical supply system equivalent circuit.

In normal operation condition, a possible load unsymmetry is low; it is equal to a capacity of one lamp.

However, the voltage drop in zero wire with low resistance $Z_{N}$ is negligible and there is almost none of voltage load unsymmetry.

Thyristors open at the angle $\alpha$, which is calculated from the transition point of the corresponding star voltage through zero value and they close when the thyristor current is equal to zero.

A relative load voltage effective value (in fractions of effective value $U_{m} / \sqrt{2}$, equal to $\alpha=0)$ is defined by formula $[5,6]$ :

$$
U=\sqrt{\frac{2}{\pi} \int_{\alpha}^{\pi} \sin ^{2} \theta \partial \theta}=\sqrt{1-\frac{\alpha}{\pi}+\sin \frac{2 \alpha}{2 \pi}} .
$$

As for the load voltage the following equation holds true: $u(\theta)=-u(\pi+\theta)$, then the function $\mathrm{u}(\theta)$ is transformed into Fourier series, which only has odd harmonics, a relative root-mean-square amplitude (in fractions of amplitude $U_{m}$ ) with $\mathrm{k} \geq 3$ is defined as follows [2]:

$\mathrm{U}_{\mathrm{k}}=\frac{\sqrt{2}}{\pi\left(\mathrm{k}^{2}-1\right)} \sqrt{\mathrm{k}^{2}+3-\left(\mathrm{k}^{2}-1\right) \cos 2 \alpha-4(\cos \mathrm{k} \alpha \cos \alpha+\mathrm{k} \sin \mathrm{k} \alpha \cos \alpha+\mathrm{k} \sin \mathrm{k} \alpha \sin \alpha}$ 
The formula (2) shows that $U_{k}=0$ when $\alpha=0$ and $\alpha=\pi$, and it also shows that the dependency $U_{k}(\alpha)$ is symmetric in $\alpha=\pi / 2$, that means the values $U_{k}(\alpha)$, corresponding to the angles $\alpha$ and $(\pi-\alpha)$ are equal between each other.

The relative amplitude value of the first harmonics $(\mathrm{k}=1)[2]$ :

$$
U_{1}=\sqrt{\left(1-\frac{\alpha}{\pi}+\frac{\sin 2 \alpha}{2 \pi}\right)^{2}+\left(\frac{\sin ^{2} \alpha}{\pi}\right)^{2}} .
$$

Harmonics multiple of zero sequence and missing linear voltage are of our main interest.

With a symmetrical load a zero wire current is determined by zero sequence load voltage, besides each zero wire current harmonics is three times higher than the load current harmonics.

$$
\mathrm{i}_{\mathrm{kN}}=\frac{3 \mathbf{u}_{\mathrm{k}}}{\mathrm{R}}, \mathrm{k}=3,9,15 \ldots
$$

For the third harmonics having $\alpha=\pi / 2$ this current has relative amplitude $3 / \pi$ (in fractions of phase current amplitude $\alpha=0$ ).

A zero wire current active value is higher than the current of any harmonics. Its relative value (relatively to the load current active value having $\alpha=0$ ) is determined by formula [2]:

$$
I_{\mathrm{N}}=\sqrt{1-\frac{3 \sqrt{3}}{2 \pi}(1+\cos 2 \alpha)} .
$$

Figure 3 shows the dependency graphs of the angle $\alpha$ of a zero wire current active value relative to the active value $I_{0}$ of phase current, the third $\frac{I_{N_{3}}}{I_{\mathrm{O}}}$ and the ninth $\frac{I_{N_{9}}}{I_{\mathrm{O}}}$ harmonics of zero wire, and also all harmonics of this current, except the third $I_{N-3} / I_{0}$.

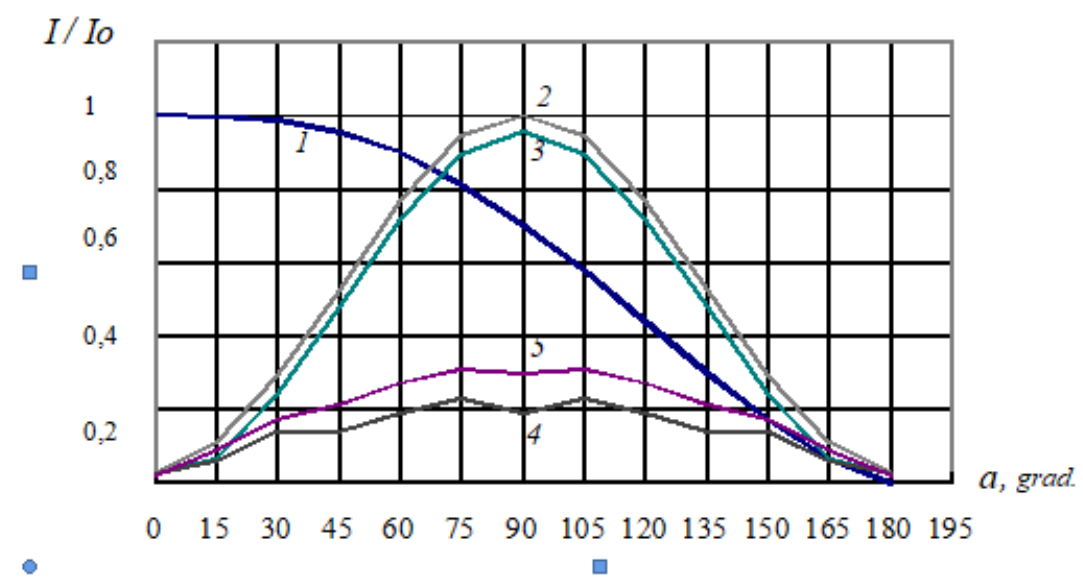

Fig. 3. Current active values dependencies of the current delay angle: 1 - phase; 2 - zero wire; 3 - its third harmonics; 4 - its ninth harmonics; 5 - all its harmonics, except the third one. 
Ship's synchronous generators zero output and generator internal conductor between stator winding connecting point and zero output are configured for the permanent current, that corresponds to $50 \%$ of generator rated current. Consequently, there is a need to limit a zero wire current.

The more the difference of the load admittance of different phases and the less the total load of converter, the more the zero wire current is. The predicted value of the first harmonics of this current is the highest, when the current delay angle equals zero, one lamp with a capacity $P_{0}$ and a resistance $R_{0}$ is switched in one phase, and two other phases have no load. That means a single-phase inverter provides a dynamic inductive load.

In this condition a zero wire current is decreasing with the current delay angle increase. On the other hand, a zero wire current is defined by zero sequence current (the third, the ninth and other harmonics) (fig.3), connected with the thyristor converter with the current delay angle $\alpha \neq 0$. The higher the total load of converter, the more the current component is.

When decreasing a zero wire current with three-phase compensation filter devices tuned to a zero sequence harmonics, it turned out that the total filter capacity of only one-third of harmonics, which decreases a zero wire current to admissible value $\mathbf{O}, 3 \boldsymbol{I}_{\mathbf{O}}$, appears to be comparable with the load power, that is why the compensation filter device is not suitable, because of its heavy load, size and cost.

It is reasonable to consider another method - with reactive impedors connecting generator and load zero points. This method is based on neutral resistance increase. On the one hand, this resistance has to be high enough to limit a zero wire current of synchronous generator to admissible value with any current delay angle value $\alpha$, on the other hand it has to be low enough so that the difference between the phase load voltage does not exceed the admissible value with given load unbalance. In order to decrease power and as a result to increase the regulator efficiency, the impedor connected between the synchronous generator and loads zero points has to be made out of reactive elements: reactors and condensers. Besides, the reactive impedor resistance on basic zero wire current harmonics frequencies can be much higher than on synchronous generator frequencies.

There is the most voltage unbalance, when the load is supplied by the highest voltage, that means $\alpha=\mathrm{O}$, providing that the load admittance of one phase $q_{a}$ is higher or lower of equal load admittance of two other phases on one lamp load admittance $\left(q_{b}=q_{c}=q\right)$. The maximum admissible impedor resistance, connected between synchronous generator and load zero points with nominal frequency $50 \mathrm{hz}[2]$ :

$$
X_{N, 50}=0,0559 \frac{U_{H}^{2}}{P_{1}},
$$

where $U_{n}$ - nominal phase generator voltage $(230 \mathrm{~W}) ; \boldsymbol{P}_{\mathbf{1}}$ - one lamp power. If $P_{1}={ }^{12000} \mathrm{~W}$, then $X_{N, 50} \approx 0,250 M$. Herewith phase load voltage differs not more than by $5 \% \boldsymbol{U}$.

Neglecting the small value of voltage decrease in synchronous generator leakage inductance, in this condition a zero wire current can be defined by the formula:

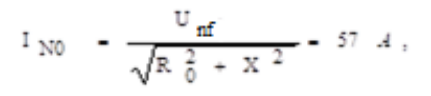

Which is 0,106 from the synchronous generator nominal current.

There is no analytical solution of weight-size parameters optimization of reactive impedor using its elements calculated installed power, because if we have thyristor voltage regulators we can define values of instantaneous current and voltage of this impedor only by numerical 
methods and for each function of input impedance the dependencies of its variables on time with the similar generator voltage and identical current delay angle are different.

Because of wide spread of capacity of capacitors and reactor coil inductance differs significantly from design value, then the reactive impedors as soon as they are installed need to be readjusted to assure the given values of impedor resistance on basic frequency and zero and pole frequencies of reactance function. This is easy to achieve in Foster chains of the I type, where the parameter change of any element causes the change of only one zero or pole [8].

While computer calculating the electric equivalent circuit with available reactive impedor variants, we have identified for each of them the filter resistance dependencies on harmonic numbers on which it is tuned and we determined relative resistance dependencies of these contours on frequency.

While considering dependencies on relative calculating frequencies i maximum current INo and integrated required capacity of impedors we found out that the minimum of integrated required capacity is $i=0,83$ (we calculated the effective values of current, voltage and power of filters for, when these variables have a maximum). It is proved that under conditions of minimizing weight and dimensional characteristics, the simplicity of device and zero wire current limitation, the best is the impedor, consisting of series connected reactor and condenser (series resonance circuit). Design values of current, voltage of this impedor and elements of different cases of unbalanced load with $i=0,83$ are shown in Table 1.

Table 1. Design values of current, voltage of this impedor and elements of different cases of unbalanced load with $\mathrm{i}=0,83$

\begin{tabular}{|c|c|c|c|c|c|c|c|}
\hline \multirow{4}{*}{$\begin{array}{c}\text { a) } \\
\mathrm{R}_{\mathrm{A}}=\mathrm{R}_{\mathrm{B}}=1,936 \mathrm{Ohm} \\
\mathrm{R}_{\mathrm{C}}=1,308 \mathrm{Ohm}\end{array}$} & $\alpha^{0}$ & $\mathbf{0}$ & 30 & 60 & 90 & 120 & 150 \\
\hline & $U_{L, B}$ & 41,64 & 54,246 & 96,279 & 132,83 & 114,51 & 85,32 \\
\hline & $U_{C, B}$ & 28,747 & 27,83 & 24,48 & 17,72 & 11,65 & 3,79 \\
\hline & $I_{N}, A$ & 51,77 & 52,86 & 55,27 & 57,44 & 49,28 & 18,53 \\
\hline \multirow{3}{*}{$\begin{array}{c}\mathrm{b}) \\
\mathrm{R}_{\mathrm{A}}=\mathrm{R}_{\mathrm{B}}=0,968, \mathrm{Ohm} \\
\mathrm{R}_{\mathrm{C}}=0,79 \mathrm{Ohm}\end{array}$} & $U_{L, B}$ & 32,63 & 50,98 & 99,24 & 142,24 & 125,1 & 100,28 \\
\hline & $U_{C, B}$ & 23,02 & 22,92 & 20,78 & 15,10 & 10,28 & 4,35 \\
\hline & $I_{N, A}$ & 40,51 & 44,65 & 50,10 & 58,81 & 51,52 & 23,769 \\
\hline \multirow{3}{*}{$\begin{array}{c}\mathrm{c}) \\
\mathrm{R}_{\mathrm{A}}=\mathrm{R}_{\mathrm{B}}=0,645 \mathrm{Ohm} \\
\mathrm{R}_{\mathrm{C}}=0,556 \mathrm{Ohm}\end{array}$} & $U_{L, B}$ & 27,99 & 48,62 & 99,94 & 144,96 & 129,22 & 116,77 \\
\hline & $U_{C, B}$ & 20,877 & 19,22 & 19,385 & 14,779 & 10,327 & 5,37 \\
\hline & $I_{N}, A$ & 34,81 & 39,86 & 49,98 & 58,39 & 53,02 & 28,75 \\
\hline \multirow{3}{*}{$\begin{array}{c}\mathrm{d}) \\
\mathrm{R}_{\mathrm{A}}=\mathrm{R}_{\mathrm{B}}=0,484 \mathrm{Ohm} \\
\mathrm{R}_{\mathrm{C}}=0,432 \mathrm{Ohm}\end{array}$} & $U_{L, B}$ & 26,49 & 45,64 & 96,756 & 146,62 & 132,5 & 119,62 \\
\hline & $U_{C, B}$ & 19,81 & 17,98 & 14,656 & 13,62 & 10,25 & 5,68 \\
\hline & $I_{N}, A$ & 34,82 & 39,82 & 42,66 & 58,38 & 53,9 & 30,28 \\
\hline
\end{tabular}

The results of computer modeling showed that the maximum wire zero current value corresponds to the case (b) when $\alpha=90^{\circ}$ and is equal to $58,8 \mathrm{~A}$, or 0,109 of nominal synchronous generator current. This current is only $0,3 \%$ higher than $\mathrm{I}_{\mathrm{No}}$. Besides the calculated reactor power is $\mathrm{Q}_{\mathrm{L}}=2,78 \mathrm{kVAr}$. The maximum value of the voltage of a capacitor corresponds to the case (a) when $\alpha=0^{\circ}$ and is equal to $28,7 \mathrm{~W}$, and the calculated output of the capacitor is $\mathrm{Q}_{\mathrm{C}}=28,7.58,8=1,69 \mathrm{kVAr}$. The maximum of gross required capacity of impedor is $\mathrm{Q}_{\Sigma \text { max }}=\mathrm{Q}_{\mathrm{L}}+\mathrm{Q}_{\mathrm{C}}=2,78+1,69=4,47 \mathrm{kVAr}$ or 0,012 of nominal synchronous generator total output.

So, the series resonance circuit has the best characteristics. While tuning the frequency on 0,83 of nominal synchronous generator frequency the gross installed capacity of this 
filter elements is 0,012 of synchronous generator total capacity, and zero wire current does not exceed 0,109 of nominal synchronous generator current.

\section{Conclusion}

The results of computer modeling showed that to define the calculated parameters of impedor elements, connected to the zero wire, we have to choose a relative rated frequency $i$ corresponding to the minimum weight and dimensional characteristics and sufficient current drop $\mathrm{I}_{\mathrm{No}}$, to identify the reactor inductance and capacitor capacity, and, by changing the angle, we have to find the maximum of voltage capacitor with single phase load of synchronous generator on one lamp and a zero wire current with $\alpha=0$. These variables allow to design reactor and to choose the capacitors correctly.

So, for the full loading of synchronous generator and decreasing the unbalance of phase voltage with unbalanced load in saury fishing it is reasonable to apply a semiconducting variable voltage regulator in four wire power supply, and the load has to be switched into the "star". To limit a zero wire current of synchronous generator it is more reasonable to use a series resonance circuit, tuned on the frequency 0,83 of the nominal one.

\section{References}

1. Kalmarolov - Sairolov [Electronic resource] // Virtus LLC. URL: https:// www.virtuschina.ru/index.php/item/45-kalmarolov-sajrolov

2. Kuvshinov G.E., Matafonova E.P. Voltage regulation of fishing lighting equipment. Study guide Vladivostok: Dalrybvtuz, 133 (2004).

3. Polukhin A. Sayra did not pass customs // Kommersant. gas No. 27, 2020

4. A powerful fleet is needed to compete in the saury fishery. [Electronic resource] // "RA Korabel.ru" LLC News 10/22/2014 // fishing, competition, china. URL:

https://www.korabel.ru/news/comments/dlya_konkurencii_na_sayrovom_promysle_nu zhen_moschnyy_flot.html/2014-22/10. Htm

5. A powerful fleet is needed to compete in the saury fishery. [Electronic resource] // "RA Korabel.ru" LLC News 10/22/2014 // fishing, competition, china №0320400001920000054. URL: https://synapsenet.ru/zakupki/fz44/0320400001920000054\%231--primorskij-krajvipolnenie-rabot-po-remontu-i

6. OnlineFreeEBooks.net// Version 2 EE IIT, Kharagpur 3. Lesson 27. Three phase AS Regulators.

7. R. Mohan Mathur, Rajiv K. Varma. Thyristor-Based FACTS Controllers for Electrical Transmission Systems, 495 (2002).

8. Zelenkov A.A. theoretical foundations of electrical engineering. Mathematical and computer modeling of processes in electric circuits. - K.: NAU, 194 (2012). 